\title{
El Caso Jesuitas, de El Salvador, en el contexto de la justicia transicional
}

\section{The Jesuit Case of El Salvador in the Context of Transitional Justice}

\author{
Eva Leticia Orduña*
}

RESUMEN: el artículo tiene el objetivo de analizar los resultados que el tratamiento del Caso Jesuitas ha tenido para cada uno de los cuatro ejes que conforman la justicia transicional. Se realiza una sistematización y análisis de los aspectos tanto nacionales como internacionales más significativos del caso, en donde se identifican también los actores principales que han intervenido. Se ofrece una panorámica integral, con la cual se logran identificar los resultados que el tratamiento del caso han tenido para los cuatro ejes de la justicia transicional: la verdad, la justicia, las reparaciones y las garantías de no repetición. Las conclusiones a las que se arribaron fueron que en materia de reparaciones y de garantías de no repetición, el tratamiento del caso ha tenido un saldo negativo en su totalidad; mientras que en materia de verdad y de justicia hay resultados mayoritariamente negativos, aunque también se han registrado algunos positivos.

Palabras Clave: Justicia Transicional; Caso Jesuitas; El Salvador; Los Crímenes del Conflicto Bélico; La Jurisdicción Universal.

ABSTRACT: The aim of this article is to analyze, from a comprehensive perspective, the results of the treatment of the Jesuit case for each of the four axes that make up transitional justice: truth, justice, reparations, and guarantees of non-repetition. A systematization and analysis of the most significant national and international aspects of the case were conducted, in which the main actors involved were also identified. The conclusions reached were that in terms of reparations and guarantees of non-repetition, the case has had a negative balance overall, whereas, in terms of truth and justice, while the results are largely negative, some positive ones have also been registered.

KeY wORDS: Transitional Justice; the Jesuit Case; El Salvador; the Crimes of the Armed Conflict; the Universal Jurisdiction.

Recibido: 14 de enero de 2019

Aceptado: 26 de junio de 2019

Centro de Investigaciones sobre América Latina y el Caribe-unAm (evaleticiaorduna@ gmail.com). Este artículo es producto del proyecto IN40021 "La verdad en Guatemala a la luz de la justicia postransicional", financiado por el Programa de Apoyo a Proyectos de Investigación e Innovación Tecnológica de la unAM. 


\section{INTRODUCCIÓN}

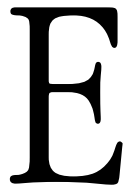

n la madrugada del 16 de noviembre de 1989 fueron asesinados seis padres jesuitas, una de sus empleadas y la hija de ésta en la residencia de los padres (la cual estaba ubicada en la Universidad Centroamericana, UCA, en San Salvador, El Salvador). Las víctimas fueron el rector de la UCA, padre Ignacio Ellacuría, de 59 años; el vicerector, padre Ignacio Martín Baró, de 47 años; el director del Instituto de Derechos Humanos de la UCA, padre Segundo Montes, de 53 años, fundador del Socorro Jurídico Cristiano "Óscar Arnulfo Romero" y presidente del Instituto de Derechos Humanos (IDHUCA) de la misma universidad, y los profesores Armando López, Joaquín López y López y Juan Ramón Moreno. Las mujeres eran la señora Julia Elba Ramos, que se desempeñaba como cocinera en la residencia, y su hija de quince años, Celina Mariceth Ramos (Comisión Interamericana 1999: I).

Los asesinatos y su tratamiento han sido conocidos como "El Caso Jesuitas". Dicho caso ha sido uno de los más relevantes en materia de justicia transicional en El Salvador. Su tratamiento ha estado determinado por una gran cantidad de aristas nacionales e internacionales, existentes tanto durante el conflicto bélico como en los años posteriores a la firma de la paz. Entre los nacionales podemos mencionar: el accionar del Estado salvadoreño durante el conflicto bélico, los arreglos político-jurídicos que se han dado entre las dos grandes fuerzas para que los crímenes realizados durante dicho conflicto permanezcan en la impunidad (resalta entre ellos la emisión de leyes de amnistía), el uso del sistema jurídico para entorpecer la justicia y mantener el poder de ciertos grupos y personas. Entre los internacionales se encuentran: el Informe de la Comisión de la Verdad para El Salvador, la actuación del Sistema Interamericano de Protección a Derechos Humanos, las acciones realizadas en España y en Estados Unidos en el contexto del principio de la jurisdicción universal. En el presente texto identificaremos los principales elementos que conforman estas aristas. 
Benjamín Cuellar, exdirector del Centro de Derechos Humanos de la Universidad Centroamericana de El Salvador, afirma que la denominación del caso es errónea, puesto que dentro de la masacre no sólo asesinaron a sacerdotes jesuitas sino también a dos mujeres (Cuellar 2017). En este escrito utilizaremos el nombre con el que usualmente se ha conocido al caso, sólo porque con ello se facilita la redacción, pero teniendo en cuenta en todo momento la dignidad de las mujeres asesinadas.

\section{EL ASESINATO DE LOS JESUITAS}

EN EL CONTEXTO DEL CONFLICTO BÉLICO

El asesinato de los jesuitas fue una de las muy graves violaciones que el gobierno salvadoreño realizó durante el conflicto bélico y se enmarca en concreto en la persecución y agresión sistemática de personas religiosas. Salvador Meléndez señala que esta persecución tuvo como símbolos de inició y de finalización dos magnicidios: el del arzobispo Óscar Arnulfo Romero, en 1981, y el de los jesuitas, en 1989 (Meléndez 2017). Los magnicidios realizados durante el conflicto bélico fueron acontecimientos de una enorme trascendencia por los efectos que tuvieron, por lo que representaban en la sociedad las personas asesinadas y porque mostraron la naturaleza y los alcances del régimen militar.

Los asesinatos de los jesuitas se realizaron en el marco del fin del conflicto bélico. Cuando se llevaron a cabo, Centroamérica era objeto de gran atención internacional, no sólo por la importancia que tenía para el mundo el cese al fuego en esta área, sino también por la gran participación que hubo en el proceso de paz por parte de diversos actores e instituciones internacionales y de distintos países. El Grupo Contadora y el Grupo de Apoyo a Contadora ya tenían muchos años buscando alternativas para la paz, e incluso el Acuerdo de Esquipulas II ya se había firmado (en 1987). A finales de 1989 se realizaron dos encuentros entre el gobierno salvadoreño y el FMLN para discutir posibilidades de paz y acordar próximas reuniones que dieran seguimiento al proceso. Estos dos encuentros fueron 
en la Ciudad México (entre el 13 y el 15 de septiembre, en donde se firmó el "Acuerdo de México") y en San José de Costa Rica (entre el 16 y el 17 de octubre).

Podría suponerse que el avance en las negociaciones de paz implicaría una disminución de la violencia política que se vivía al interior de El Salvador, pero no fue así. Dicha violencia, por el contrario, se exacerbó de una manera muy intensa. Muy cercano al día del asesinato de los jesuitas, se realizaron dos atentados a través del accionar de bombas. El primero fue el 31 de octubre, en las oficinas del Comité de Madres de Desaparecidos y Presos Políticos de El Salvador (COMADRES), en el cual hubo seis personas heridas de gravedad, dos de las cuales eran niños. El mismo día, pocas horas después, explotó otra bomba en el interior del edificio de la Federación Nacional Sindical de Trabajadores Salvadoreños (Fenastras), que mató a diez personas e hirió a 35.

Seis días antes del asesinato de los padres jesuitas (el 11 de noviembre), el FSLn lanzó una gran ofensiva, la cual fue contrarrestada por el gobierno a través de diversas acciones militares, del endurecimiento de sus políticas y de actos violentos e ilegales. Una de las medidas tomadas por el gobierno fue la imposición del estado de sitio, el cual, a su vez, produjo violaciones adicionales a los derechos humanos. El país y, en especial, la capital, se encontraban entonces en una gran conmoción. En este marco, según la Comisión Interamericana de Derechos humanos (CIDH), "se produjeron actos de extrema gravedad que han tendido a acentuar sus negativos efectos y a complicar la solución pacífica y negociada del mismo. La grave situación planteada afectó la totalidad de derechos humanos, provocando un acentuado deterioro" (Comisión Interamericana 1990).

En este contexto, fueron asesinadas, mediante un plan previa y cuidadosamente diseñado por estructuras estatales y militares, personas que también habían abogado y trabajado por el fin del conflicto bélico y que definitivamente no eran parte de éste. El régimen militar señalaba continuamente que los sacerdotes jesuitas de la UCA (en especial el padre Ignacio Ellacuría) eran aliados o incluso parte del FmLN. En el Informe de la Comisión Interamericana de Derechos Humanos del Caso Jesuitas se 
consignan algunas de estas acusaciones: en el párrafo 14 se menciona que el presidente Napoleón Duarte acusó públicamente al padre Ignacio Ellacuría de ser el "creador de la teoría y la concepción de rebeldía de los guerrilleros"; en el 15 se señala que el Coronel Juan Orlando Zepeda "expresó que el asesinato de un fiscal general había sido planificado dentro de la UCA y se refirió a dicho centro académico como "un refugio de líderes terroristas desde donde se planea la estrategia de los ataques contra los salvadoreños"', y en el párrafo 17 se establece que "el vicepresidente de El Salvador, Francisco Merino, acusó al padre Ellacuría de haber 'envenenado las mentes de los jóvenes de El Salvador"” (Comisión Interamericana 1999).

Este tipo de señalamiento se hacía con el fin de eliminar las voces que cuestionaban la actuación del Estado y que pedían justicia social al interior del país. El sistema de inteligencia (sofisticado, equipado, eficiente, profesional) con el que contaba el Estado salvadoreño le permitía al régimen militar estar seguro de que los sacerdotes jesuitas no apoyaban en concreto la ofensiva que el FMLN en ese entonces había desplegado, ni a este Frente como tal en ningún momento del conflicto bélico.

\section{LAS VARIABLES INTERNAS}

En El Salvador ha existido impunidad casi completa en relación con los crímenes cometidos durante el conflicto bélico. Ésta ha sido conseguida a través de la manipulación del sistema jurídico, de medidas político-jurídicas (entre las que se cuentan de manera especial la emisión de dos leyes de amnistía), del intento de la sustracción a la supervisión internacional en materia de derechos humanos y de las resistencias ante las acciones realizadas con base en el principio de la jurisdicción universal.

Las acciones que desde el Estado salvadoreño se realizaron desde que se conocieron los asesinatos de los jesuitas fueron completamente ineficientes para lograr el esclarecimiento real de los hechos y el establecimiento de responsabilidades y, por el contrario, consiguieron el encubrimiento de los responsables. 
Las primeras acciones que se llevaron a cabo frente al caso fueron encomendar la investigación a organismos poco aptos, que en realidad sirvieron para destruir o distorsionar evidencias y para sustraer de la atención judicial a la mayoría de los autores, tanto intelectuales como materiales. Estos dos organismos estaban dirigidos por personal de la Fuerza Armada, con lo cual era claro de primera instancia que no actuarían con imparcialidad e independencia. Al día siguiente de los asesinatos, el presidente Alfredo Cristiani asignó la investigación a la Comisión de Investigación de Hechos Delictivos (CIHD), la cual fue "un cuerpo especial creado en 1985 con fondos de la AID (Agencia Internacional para el Desarrollo). Su cometido inicial fue investigar aquellos casos constitutivos de violaciones a los derechos humanos, en los que estuvieren implicados miembros de la Fuerza Armada" (Artucio 1991: 35). Dos meses después de iniciado el trabajo, la CIDH no había mostrado resultado alguno.

Probablemente la asignación del caso a esta instancia se realizó con la esperanza de que los hechos dejaran de ser de atención nacional e internacional. No obstante, esto no sucedió así.

Recordemos que, especialmente debido al proceso de paz que se estaba realizando para Centroamérica y al consenso que existía en el ámbito mundial por la creación de sistemas democráticos, hubo muchas manifestaciones (tanto de organismos civiles internacionales, como de las Naciones Unidas y de diferentes países en lo particular) para que el caso de los jesuitas fuera esclarecido. Una de las presiones más fuertes vino de parte de Estados Unidos, quien amenazó con retirar asistencia económica a El Salvador si éste no atendía el caso.

Las intenciones que Estados Unidos tuvo al involucrarse son difíciles de identificar y también lo son las posibles negociaciones que tuvo con el gobierno de El Salvador. Cuando se hizo pública esta amenaza (5 de enero de 1990), el presidente Cristiani encomendó la investigación a una Comisión de Honor de la Fuerza Armada (la cual estuvo integrada por seis oficiales superiores de la Fuerza Armada y dos abogados civiles). Como puede observarse, esta Comisión adolecía de los mismos vicios que la CDHI. Sin embargo, identificó en el mismo día en que fue creada a nueve 
responsables de los asesinatos. En el expediente del caso, la Comisión de Honor no explicó en qué se basó para llegar a sus conclusiones. Para poder analizar el involucramiento que Estados Unidos tuvo en el caso, debemos tomar en cuenta que el gobierno de éste está compuesto por actores con fuerzas e ideologías divergentes. Quizá desde el Congreso (lugar desde el cual se realizó la amenaza de suspensión de la asistencia económica a El Salvador), existía un verdadero interés porque en este país se detuvieran las violaciones a los derechos humanos y se transitara hacia un Estado de derecho. No obstante, otros actores de poder, concretamente aquellos que tuvieron una responsabilidad (ya sea por la canalización de ayuda militar y económica como por la asesoría al régimen militar salvadoreño y capacitación a efectivos de éste) en las violaciones graves a los derechos humanos realizadas en el país centroamericano, pudieron no haber tenido el deseo de que realmente se esclareciera el Caso Jesuitas. Lo cierto es que la investigación que realizó la Comisión de Honor, además de estar también plagada de irregularidades e inconsistencias, impidió que los altos mandos dentro del Ejército pudieran ser objeto del escrutinio judicial. Toda la atención se canalizó hacia las nueve personas que, sin ningún sustento, habían sido identificadas como responsables por la Comisión de Honor. Dos situaciones sugieren que ciertos sectores de Estados Unidos tenían interés de que no se reconociera como responsables a los altos mandos: la primera es la filtración de que un testigo señaló en Estados Unidos como responsable de los asesinatos al coronel Benavides (quien fue posteriormente una de las dos personas que purgaron cárcel y de quien se dice que en realidad es el "chivo expiatorio"). La segunda es el cambio de testimonio ante el FBI de una persona que presenció los hechos.

Las acciones judiciales realizadas tanto en la etapa el conflicto bélico como en la que siguió a la firma de los Acuerdos de Paz fueron igual de burdas y sin un real sustento legal. Se intentó, al igual que se hizo en las dictaduras y regímenes autoritarios existentes en América Latina en el pasado inmediato, utilizar el derecho para legitimar injusticias. 
En un primer momento, la investigación y el juicio se realizaron a través del sistema jurídico entonces existente en El Salvador: un sistema arcaico en el que el juez que conocía el sumario era el mismo que conocía el plenario, y en el cual quien decidía sobre la inocencia o responsabilidad de los acusados era un jurado popular.

En la fase del sumario, fue al juez al que le correspondió establecer la presunta responsabilidad de los denunciados, pero las actividades propiamente de la investigación estuvieron a cargo de la CIHD. Tanto la fase del sumario como la del plenario fueron sumamente deficientes. Dos de los fiscales del caso, los abogados Henry Campos y Sidney Blanco, renunciaron en enero de 1991 en protesta por la manera en que había llevado la fase del sumario. En el Informe de la Comisión Interamericana se señala de ello:

Dichos exfuncionarios del Estado señalaron en una entrevista televisiva que no existió voluntad de investigar por parte de los organismos oficiales. En aquella entrevista, los exfiscales señalaron que renunciaron a sus cargos porque la Fiscalía General les había puesto todo tipo de obstáculos para impulsar una investigación seria y completa de las ejecuciones extrajudiciales (Comisión Interamericana 1990).

En relación con las deficiencias del juicio en sí mismo, podemos resaltar el hecho de que no se conocieron los nombres de los integrantes del jurado popular, que éste no tomó en cuenta importantes pruebas que incriminaban a los miembros del batallón Atlacalt y que el juez no aceptó pruebas que presentaron los acusadores particulares. Rodolfo Cardenal señala respecto a las deficiencias:

Dos de los fiscales de ese proceso declararon ante el juez español que el Fiscal General no sólo les ordenó no investigar el asesinato, sino que también entorpeció su trabajo. Consta, asimismo, que las declaraciones de los soldados fueron reelaboradas por un abogado de la Fuerza Armada, ahora convertido en un destacado político demócrata. Existe evidencia de que el jurado fue aleccionado por un alto funcionario gubernamental, ajeno al juicio, cuya secretaria, además, fue integrante de dicho jurado (Cardenal 2011: 5). 
En el juicio se estableció la responsabilidad del coronel Guillermo Alfredo Benavides (director de la Escuela Militar), del teniente coronel Carlos Camilo Hernández Barahona (director adjunto de la Escuela Militar) y de los oficiales de la Escuela Militar Ricardo Espinoza, Gonzalo Guevara, y Camilo Hernández. Los dos primeros fueron sentenciados a prisión y los tres últimos quedaron libres bajo fianza e incluso continuaron activos dentro de la Fuerza Armada. Ningún miembro del batallón Atlacatl fue encontrado responsable.

La acción más significativa para impedir el establecimiento de responsabilidades (no sólo por el caso de los jesuitas, sino por todos los crímenes realizados en el conflicto bélico) fue la emisión, en 1993, de la Ley de Amnistía General para la Consolidación de la Paz (LAGCP).

La LAGCP permitió que los dos únicos sentenciados por el Caso Jesuitas salieran de prisión. No obstante, seguramente la libertad de estas personas era lo menos que interesaba a aquellos que la diseñaron, aprobaron y sancionaron. Debido a ella, se inhibieron las posibles acciones de investigación y sanción real por los asesinatos. Dicha amnistía, a pesar de ser uno de los elementos más significativos de impunidad, no fue el único con el que se consiguió ésta. En realidad, todo el sistema del Estado, especialmente el jurídico, obedecía a conseguir dicho objetivo. Cuando en 2000 el rector de la Universidad Centroamericana, junto con el director y otro colaborador del Centro de Derechos Humanos de esta Universidad, interpusieron una nueva denuncia en relación con el caso, no fue la Amnistía de 1993, sino la prescripción del delito, la razón final que se presentó para desecharla. ${ }^{1}$

1 El análisis jurídico del proceso que se llevó a cabo a raíz de la presentación de la denuncia en 2000 es muy complejo, debido a los diferentes recursos que se tuvieron que presentar por parte de los denunciantes y de las distintas instancias que los conocieron. Por ejemplo, El fiscal general que conoció de la denuncia en primera instancia se negó a actuar con dos argumentos principales: 1) el caso ya había sido juzgado en 1991 y los sentenciados amnistiados en 1993 por la LAGCP (aun cuando los acusados no eran los mismos que en 1991) y 2) Esta Ley le impedía cualquier acción en relación con el caso. Como puede verse, en un principio sí fue la LAGCP el argumento con el cual se negaron a actuar las autoridades, pero la última razón para desechar toda 
Sólo en un sistema estatal diseñado para mantener la impunidad era posible que este argumento contrario a derecho y que atentaba incluso contra la dignidad de las víctimas y de los denunciantes fuera considerado como válido. La Corte Suprema de Justicia estableció que, tomando en cuenta que el lapso para interponer una denuncia por homicidio era de diez años, éste ya había fenecido en 1999. Desacreditó los argumentos de los denunciantes en relación con que la prescripción jurídicamente no operaba debido a la LAGCP, la cual se usó por todos los fiscales para negarse a iniciar todo trámite respecto al caso. Señaló en concreto que: "lo impróspero de la acción ejercida no es atribuible a la negación, sino al propio ánimo de los afectados en dejar pasar el tiempo al momento de ejercer su acción, olvidando que los derechos nacen, a lo largo del tiempo se ejercen, pero también se extinguen" (Escalante 2016: 188).

El encubrimiento de los responsables del Caso Jesuitas antes de la firma de los Acuerdos de Paz pudo ser atribuido a un sistema político y jurídico antidemocrático y autoritario, propio del régimen militar que se vivió durante el conflicto armado. No obstante, una vez terminado éste se mantuvo la misma tendencia. Incluso, se puede señalar que las acciones que se realizaron desde el Estado para mantener la impunidad en este caso fueron más claras y decididas que en el pasado inmediato, debido a que tuvieron que contrarrestar las ejercidas desde el exterior (especialmente las relacionadas con el proceso iniciado en España) para que se lograra justicia.

Los muy pobres resultados que en materia de justicia transicional se han alcanzado en El Salvador se deben en gran medida a la decisión de la clase política que surgió a raíz de la firma de los Acuerdos de Paz de bloquear todo intento de esclarecimiento histórico y de establecimiento de responsabilidades. Tanto los gobiernos de Arena como los del FmLn que se han sucedido han promovido políticas conocidas como de perdón y olvido respecto del pasado inmediato. Para ello se han abocado al diseño de instituciones estatales, a la aplicación de mecanismos político-jurídicos y

acción fue la prescripción del delito. Para un análisis de todas las etapas del proceso véase Escalante 2016. 
a la realización de diversas acciones dentro de los tres poderes del Estado (Judicial, Ejecutivo y Legislativo).

LAS VARIABLES INTERNACIONALES

\section{El informe Comisión de la Verdad}

La tendencia generalizada en todo el mundo a la creación de Comisiones de la Verdad y la fuerte participación internacional en el proceso de pacificación obligaron a las partes del conflicto bélico a aceptar el establecimiento de una Comisión de la Verdad dentro de los Acuerdos de Paz. Éste ha sido el único trabajo importante interno oficial que se ha realizado en El Salvador en relación con el establecimiento de la verdad. Dicho trabajo, no obstante, fue sumamente reducido tanto en lo que se refiere al tiempo en que fue realizado (nueve meses), como a los resultados que entregó. 198 páginas componen el informe final, en el que se incluyeron tan sólo casos ilustrativos y en el que no se realizó un balance general de las violaciones graves y sistemáticas a los derechos humanos efectuadas durante el conflicto bélico. No se identificó el número total de personas asesinadas, torturadas o desaparecidas, o el de masacres perpetradas.

El caso jesuitas fue incluido como el primero de los casos ilustrativos contenidos en el Informe de la Comisión de la Verdad. En él se hizo mención del juicio interno celebrado, cuya sentencia se emitió en septiembre de 1991 y se identificó como responsables a 20 personas (entre los que se encontraron altas autoridades del Estado, miembros del batallón Atlacatl, e incluso miembros de la Comisión de Honor que investigó los asesinatos), por haber encubierto a los responsables reales. Entre las altas autoridades militares, incluyó a los entonces jefe del Estado Mayor Conjunto de las Fuerzas Armadas (René Emilio Ponce), comandante de la Fuerza Aérea Salvadoreña (Juan Rafael Bustillo), viceministro de Defensa Nacional (Juan Orlando Zepeda), viceministro de Seguridad Pública (Inocente Orlando Montano), director de la Escuela Militar (Guillermo Alfre- 
do Benavides). Concluyó también que era injusto que el autor material (Benavides) estuviera en prisión, cuando los autores intelectuales estaban libres (punto 9). En el informe también se incluye una descripción de los hechos, el contexto político-militar en el que se dieron los asesinatos, el proceso mediante el cual se encubrió a los autores intelectuales.

Ante la carencia de justicia interna y la impunidad con las cuales los autores intelectuales se vieron protegidos desde que los asesinatos fueron cometidos, las conclusiones de la Comisión de la Verdad fueron un gran logro precisamente para el establecimiento de la verdad en El Salvador. Estas conclusiones, además, fueron tomadas en cuenta en acciones que se efectuaron posteriormente en relación con el caso: la Comisión Interamericana de Derechos Humanos y la Audiencia Nacional española las tomaron como fuente de sus propias investigaciones y sirvieron también de impulso para el proceso interno que se trató de realizar en 2000.

A nuestro modo de ver, no obstante, las conclusiones de la Comisión de la Verdad respecto a este caso tienen dos fallas fundamentales. La primera es el que caso se incluye en el apartado titulado "Violencia contra los opositores por parte del Estado", cuando ni los sacerdotes jesuitas ni las mujeres que murieron eran opositores del Estado. Al estar el caso en el apartado con este título se concede un poco de razón al régimen militar cuando durante el conflicto bélico identificó a la UCA como un bastión del FMLN y a los sacerdotes jesuitas como parte del mismo Frente. La segunda falla y que en realidad es una incongruencia a lo largo de todo el informe es no incluir al entonces presidente Alfredo Cristiani como parte de los responsables intelectuales. ${ }^{2}$ Según el concepto de la responsabilidad de mando, el superior, aun cuando no haya cometido un crimen por sí mismo, es responsable por los realizados por sus subordinados por no prevenirlos o castigarlos. Las personas identificadas en el Informe de la Comisión de la Verdad como responsables de los asesinatos eran subordinados del presidente Cristiani y por este solo hecho, aún y cuando el presidente

2 En la denuncia presentada en 2000 sí se incluye a Cristiani como uno de los responsables, también se le incluyó inicialmente en la querella presentada en España, pero después se retiró su nombre. 
no hubiera participado en la decisión y planeación de los crímenes, era responsable por no haberlos prevenido ni perseguido. Además, las muertes no formaron parte de la generalidad de crímenes cometidos durante el conflicto bélico. Representaron un caso excepcional al haber sido perpetradas hacia personas de alta jerarquía académica, que también formaban parte de un grupo religioso con gran influencia interna y externa, y que además en su mayoría eran nacionales de otro país. Es difícil que una decisión de este tipo (que tendría consecuencias en diversas áreas, tanto nacionales como internacionales) hubiera escapado del conocimiento del presidente del Estado salvadoreño, quien formalmente era el comandante supremo de las Fuerzas Armadas.

\section{El Informe de la Comisión Interamericana de Derechos Humanos}

El 16 de noviembre de 1989 la organización Americas Watch presentó ante la Comisión Interamericana una petición en la que denunció los asesinatos de los jesuitas y de sus colaboradoras. Diez años después (el 22 de diciembre de 1999) la Comisión emitió el informe núm. 136/99 sobre el caso. Estas fechas en principio revelan dos situaciones. En primer término, la rapidez de reacción de la organización no gubernamental, dado que la petición fue presentada el mismo día de los asesinatos. En segundo término, el largo tiempo que le llevó a la Comisión resolver el caso. La petición fue presentada originalmente de manera exclusiva por los asesinatos, ya que en el momento era la única violación a los derechos humanos que se había realizado. No obstante, durante el tiempo en que estuvo en trámite, la Comisión tuvo oportunidad de analizar y de pronunciarse sobre las violaciones restantes que se fueron presentado.

El informe constituye un documento muy valioso no sólo en términos jurídicos sino también en los históricos. En él se contiene información de las múltiples y muy evidentes anomalías con las cuales el caso fue tratado por el Estado salvadoreño. En primer término, los peticionarios 
(es decir, Americas Watch) aportaron información acerca de las irregularidades que se presentaron en: la Comisión de Investigación, la Comisión de Honor, la Fiscalía General, y en los procedimientos penales y las maniobras procesales posteriores al juicio (párrafos 27 a 37).

En el momento de hacer el análisis de fondo, la Comisión profundizó sobre las anomalías presentadas en torno a los exfiscales Henry Campos y Sidney Blanco, los informes concordantes sobre las investigaciones y el juicio por el asesinato de los jesuitas, las investigaciones de la Comisión de Investigación y de la Comisión de Honor, la política de encubrimiento y sus destinatarios (en el que se incluyó al Batallón Atlacatl, la política de encubrimiento del Estado Mayor Conjunto, el proceso simulado, el veredicto del jurado y la sentencia) (párrafos 87 a 142). Sostenemos que el informe tiene también un valor como fuente histórica, porque además en él se hace un estudio del contexto histórico en el cual ocurrieron los asesinatos, es decir, de la última etapa del conflicto armado.

El análisis jurídico que la Comisión hizo no fue en relación con los procedimientos judiciales internos, sino por las violaciones a la Convención Interamericana de Derechos Humanos. Puesto que los acontecimientos se realizaron en el marco de un conflicto bélico, también aplicó el Derecho Internacional Humanitario. La Comisión identificó que el Estado salvadoreño había violado el derecho a la vida (artículo 4 de la Convención Americana, y de los principios codificados en el artículo 3 común de las Convenciones de Ginebra), el deber de investigar y sancionar (artículo 1(1) de la Convención Americana), el derecho a las garantías judiciales y a la tutela judicial efectiva (artículos 8 [1] y 25 de la Convención). Además, analizó de forma amplia la LAGCP y concluyó que ésta era incompatible con la Convención Americana. Este último punto es de especial relevancia, pues con el informe se fortalece la construcción jurídica que tanto la Comisión como la Corte Interamericana han venido elaborando en torno a la ilegalidad de este tipo de leyes. En el informe que estamos comentando, además de determinarse que la emisión y vigencia de la LAGCP fueron violatorios de los preceptos de la Convención Americana, también se identificó la forma en la cual impidió la justicia en el caso de los jesuitas. 
En el contexto del estudio de la LAGCP, también se analizó el derecho a la verdad, en el cual el Sistema Interamericano de Derechos Humanos ha tenido un papel muy importante. En el presente informe la Comisión sostuvo, entre otras cuestiones importantes: "El derecho a la verdad es un derecho de carácter colectivo que permite a la sociedad tener acceso a información esencial para el desarrollo de los sistemas democráticos y a la vez un derecho particular para los familiares de las víctimas, que permite una forma de reparación, en particular, en los casos de aplicación de leyes de amnistía" (párrafo 224).

Las recomendaciones que la Comisión formuló al Estado salvadoreño fueron (párrafo 241):

1. Realizar una investigación completa, imparcial y efectiva, de manera expedita, conforme a estándares internacionales, a fin de identificar juzgar y sancionar a todos los autores materiales e intelectuales de las violaciones encontradas, sin perjuicio de la amnistía decretada.

2. Reparar integralmente las consecuencias de las violaciones enunciadas, incluido el pago de una justa indemnización.

3. Adecuar su legislación interna a los preceptos de la Convención Americana, a fin de dejar sin efecto la ley conocida como de Amnistía General.

A pesar de la gravedad de los hechos denunciados y de la evidente responsabilidad del Estado, el caso no pudo ser elevado ante la Corte Interamericana de Derechos Humanos, con lo cual se fortaleció la impunidad que ha existido alrededor de él. En el momento en que el caso fue conocido por la Comisión, El Salvador tenía la decisión férrea de negarse a que la Corte Interamericana conociera de hechos sucedidos durante el conflicto bélico. Durante mucho tiempo invocó la limitación temporal que presentó en el instrumento en el cual reconoció la competencia contenciosa de la Corte. ${ }^{3}$ Esta situación cambió a partir de 2009, cuando el

3 En la limitación temporal se señala: "El Gobierno de El Salvador, al reconocer tal competencia [de la Corte Interamericana], deja constancia que su aceptación se hace por plazo indefinido, bajo condición de reciprocidad y con la reserva de que los casos en que se reconoce la competencia, comprende sola u exclusivamente hechos o actos jurídicos posteriores o hechos o actos jurídicos cuyo principio de ejecución sean 
Estado decidió dejar de invocar la limitación temporal y con ello la Corte pudo conocer de ciertos casos denunciados después de esta fecha.

\section{Los procesos en torno a la jurisdicción universal}

El 13 de noviembre de 2008, la Asociación pro Derechos Humanos de España, y el Center for Justice and Accountability (Centro de Justicia y Responsabilidad) presentaron en Madrid, España, una querella contra los autores materiales e intelectuales de los asesinatos de los padres jesuitas y sus colaboradoras, por crímenes de lesa humanidad y terrorismo o asesinato en el contexto de crímenes contra la humanidad, con base en el principio de la jurisdicción universal. El 12 de enero de 2009, el juez Velasco admitió la querella.

Una de las razones principales por las cuales la Audiencia Nacional de España admitió la querella del Caso Jesuitas fue la impunidad existente en El Salvador respecto a él. Para la Audiencia Nacional española fue relativamente sencillo concluir que en el sistema interno salvadoreño no se había logrado justicia en relación con el caso, debido a que las dos únicas personas que habían estado cumpliendo pena de prisión habían sido liberadas gracias a la LAGCP. Este hecho, a pesar de ser contundente, no fue el único que fue tomado en cuenta. También se consideró la totalidad de las medidas que de forma sistemática tomó el Estado para impedir una investigación y un juicio reales y eficaces, y con lo cual se logró el encubrimiento de los verdaderamente responsables.

La actitud de gobiernos tanto de Arena como del FuLN frente al proceso en España fue la misma que la presentada en relación con la justicia interna: obstaculizarlo. Durante el gobierno de Francisco Flores, del partido Arena, se conoció y desechó la denuncia interna interpuesta en 2000 por el rector de la UCA. También durante este gobierno, la Corte Suprema de Justicia de El Salvador acordó no brindar la asistencia judicial solicitada

posteriores a la fecha del depósito de esta Declaración de Aceptación" (Estado de El Salvador 1995). 
por la Audiencia Nacional de España. Básicamente los motivos fueron los siguientes: 1) las personas que serían juzgadas en España ya habían sido procesadas en El Salvador. 2) la solicitud afectaría el proceso de paz y de reconciliación y era contraria al interés esencial de El Salvador (a través del que se buscaba superar los actos de violencia de la guerra). Ambos fueron argumentos jurídicamente insostenibles. Las personas señaladas como responsables en la querella en España eran diferentes a las que habían sido juzgadas en El Salvador, y no puede sostenerse que el esclarecimiento de los asesinatos pudiera afectar el proceso de paz. La UCA manifestó al respecto:

Si buscar justicia es un problema en una sociedad, algo anda mal en la misma, pues son los tribunales el lugar apropiado para ventilar las injusticias. Si presentar una demanda resulta inadmisible porque abre heridas en la parte acusada, entonces habría que prescindir del sistema judicial, puesto que todo proceso es doloroso para las partes enfrentadas... La administración de justicia independiente no representa ninguna amenaza, excepto para sus transgresores y para quienes todavía están dispuestos a utilizar la fuerza para imponer la ley (UCA 2011: 3).

El magistrado Florentín Meléndez señaló en relación con la negativa de asistencia judicial fundada en proteger el interés esencial de El Salvador:

Se fundamentó también la denegación de asistencia judicial en que el pedido de cooperación para esclarecer y juzgar graves violaciones de derechos fundamentales, es contrario a los "intereses esenciales" del país, invocando para ello el art. 6 literal d) del Convenio.

La afirmación sostenida por los magistrados que suscriben la Resolución de Corte Plena es un equívoco jurídico, ya que contradice las obligaciones internacionales del Estado salvadoreño en materia de derechos humanos y en materia de cooperación judicial, para la investigación, esclarecimiento y sanción de los culpables de cometer "crímenes de lesa humanidad"; y contradice también las obligaciones contenidas en el mismo Convenio bilateral y en los Principios de Cooperación Internacional en la Identificación, Detención, Extradición y Castigo de los Culpables de Crímenes de Guerra y de Lesa Humanidad, aprobados por la Asamblea General de Naciones Unidas (3 de diciembre de 1973), principios mediante los cuales todos los Estados Miembros están obligados a cooperar y prestarse 
ayuda mutua en la identificación, detención y enjuiciamiento de los presuntos autores de tales crímenes, y cooperar en la compilación de informaciones y documentos relativos a la investigación a fin de facilitar el enjuiciamiento de las personas involucradas (Meléndez 2010).

Durante los gobiernos de Mauricio Funes y de Salvador Sánchez Cerén (ambos del FMLN) se siguieron rechazando las acciones realizadas desde la Audiencia Nacional de España y protegiendo a quienes se había identificado como procesables por ésta.

Ante las notificaciones rojas ${ }^{4}$ y la solicitud de extradición emanadas desde España, los exmilitares señalados se presentaron ante la Brigada Especial de Seguridad Militar de El Salvador señalando que se constituían en detención preventiva voluntaria, mientras la Corte Suprema de Justicia de El Salvador resolvía sobre la procedencia de la solicitud de extradición. En esta Brigada permanecieron resguardados. Es relativamente comprensible que los militares que ejercieron el poder durante el conflicto bélico se protegieran entre sí mismos. No obstante, también encontraron protección, concretamente ante las solicitudes de España, por parte de quienes fueron sus enemigos en el pasado inmediato. En 2000, era presidente (y por lo tanto comandante de la Fuerza Armada) de El Salvador, Mauricio Funes, y los exmilitares señalados por España pudieron refugiarse sin ningún problema en las instalaciones militares. Durante su gestión, Funes pidió perdón, en nombre del Estado, por la masacre de El Mozote. No lo hizo por el de los jesuitas y en cambio ascendió a militares que habían sido señalados como responsables. En la editorial del número 745 de la Revista Eca se señala al respecto:

En el caso jesuitas, en noviembre del año 2009, el presidente Funes les otorgó, póstumamente, a los masacrados de la UCA, la orden Matías Delgado, máxima condecoración que da la Presidencia de la República. Pero aunque reconoció el valor y los servicios de los jesuitas, no pidió perdón

4 Una notificación roja sujeta a ejecución por la Interpol es aquella mediante la cual se ordena la captura de ciertas personas. El caso que estamos estudiando, el juez Velasco emitió en junio de 2011 notificaciones rojas en contra de 20 exmilitares salvadoreños y las envió a la Interpol para que las ejecutara. 
en nombre de la Fuerza Armada, siendo el comandante supremo de la misma según la Constitución (Revista Eca 2016: 165).

El sistema jurídico operó en el mismo sentido. En agosto de 2001, la Corte Suprema de Justicia de El Salvador señaló entre otras cosas: 1) que la notificación roja es un aviso de localización y no de captura; 2) que no había recibido la solicitud de extradición.

Durante el gobierno de Sánchez Cerén, si bien se realizó un avance significativo en materia de justicia transicional (al reconocerse como inconstitucional la LAGCP), la protección en relación con el caso jesuitas se mantuvo. Dentro de su campaña presidencial tuvo como asesor a un militar señalado como responsable de los asesinatos. En febrero de 2016, la Audiencia Nacional de España volvió a pedir la captura de ciertas personas y la Policía Nacional Civil (dependiente del Poder Ejecutivo) no las ejecutó de inmediato, como jurídicamente procedía.

El caso jesuitas aún sigue en proceso dentro de la Audiencia Nacional. No obstante, las reformas a la Ley Orgánica del Poder Judicial de España que se emitieron en 2014 y 2016, ${ }^{5}$ lo afectaron seriamente. El 31 de marzo de 2014 el juez español Velasco aceptó que, en virtud de la reforma, no podía investigar ni juzgar a los exmilitares por el delito de lesa humanidad, sino sólo por los asesinatos terroristas y únicamente en relación con las cinco víctimas de nacionalidad española.

En Estados Unidos también se han realizado algunas acciones respecto al caso jesuita. Éstas han sido parte de un proceso más amplio que se ha seguido respecto a responsables de violaciones graves a los derechos humanos, procedentes de países latinoamericanos, en el cual se han emitido condenas por fraudes migratorios y por torturas, por una parte, y se han ordenado deportaciones y extradiciones, por la otra. Como consecuencia de las condenas por fraudes, se han cancelado naturalizaciones o permisos migratorios de antiguos represores, al haberse comprobado falsedad de declaraciones de éstos en sus solicitudes. Respecto al caso jesuitas,

5 La reforma de 2014 limitó fuertemente la jurisdicción universal y la de 2016 prácticamente la anuló. 
en agosto de 2011 se detuvo en Estados Unidos, para ser procesado por fraude migratorio, al excoronel Inocente Montano (quien es uno de los señalados en la querella interpuesta en España como responsable del asesinato de los jesuitas y era viceministro de Defensa de El Salvador cuando éstos se cometieron). Según el periódico El Faro (2015): "El comunicado no deja resquicios para las interpretaciones. Estados Unidos acepta entregarle a España a un exmilitar salvadoreño contra quien la justicia estadounidense documentó responsabilidad en unas mil graves violaciones a los derechos humanos, incluidos 65 asesinatos, y de participar en una de las últimas masacres cometidas al final de la guerra civil".

Con base en dos ordenamientos jurídicos internos (Alien Tort Claims Act, de 1789 (ATCA o ATS) y Torture Victim Protection Act) se ha ordenado que diversos represores paguen indemnizaciones civiles. Del Toro Huerta nos dice en relación con la primera: "La historia de la aplicación de la ATCA ha conocido de demandas por diferentes violaciones de normas internacionales, entre ellas: tortura, genocidio, violencia sexual, crímenes de guerra, esclavitud y trabajos forzados, apartheid, ejecuciones extrajudiciales, tratos inhumanos y degradantes, daños graves al ambiente, desapariciones forzadas" (Del Toro 2017: 336).

En 2002 un jurado de West Palm Beach, Florida, Estados Unidos, encontró a Vides Casanova, y a su antecesor, José Guillermo García, culpables de torturas, y fueron condenados a pagar "una indemnización por 54.6 millones de dólares" (El Mundo 2011).

En relación con deportaciones y extradiciones, se encuentran los casos de Eugenio Vides Casanova (quien fue deportado hacia El Salvador en abril de 2015) y del coronel Inocente Montano (quien fue extraditado de Estados Unidos en 2017). Vides Casanova fue jefe de la guardia nacional de El Salvador entre los años 1979 y 1983. De 1983 a 1989 tuvo el cargo de ministro de Defensa de la nación. Es señalado como responsable de graves violaciones a derechos humanos, incluidos los asesinatos de los jesuitas. 


\section{CONCLUSIONES}

La sistematización y análisis de las variables, tanto nacionales como internacionales, que han intervenido en el caso jesuitas nos permite identificar las consecuencias que su tratamiento ha tenido para los cuatro ejes de la justicia transicional.

Podemos señalar globalmente que en materia de reparaciones y de garantías de no repetición, el tratamiento del caso ha tenido un saldo completamente negativo; mientras que en materia de verdad y de justicia hay resultados mayoritariamente negativos pero también se han registrado algunos positivos.

Los resultados negativos en materia de reparaciones son claros. En el ámbito interno no se ha establecido nada al respecto. Muchas de las víctimas y/familiares de violaciones graves y sistemáticas a los derechos humanos realizadas durante el pasado inmediato en América Latina, que no han encontrado en los sistemas internos ninguna clase de justicia y de reparación, se han visto beneficiadas por las reparaciones ordenadas por la Corte Interamericana de Derechos Humanos. En el Caso Jesuitas, al no haberse llevado el juicio ante la Corte por las razones esgrimidas anteriormente, no fue posible el establecimiento de reparaciones. En ámbito de la jurisdicción universal tampoco se ha logrado esto. El juicio que se lleva a cabo en España, aun cuando sigue su curso, tiene pocas posibilidades de llegar a buen fin, con lo cual se ve muy remoto que puedan establecerse reparaciones para los familiares de las víctimas. Las reparaciones ordenadas por la vía civil son uno de los mayores logros de los procesos emprendidos por Estados Unidos y en concreto, como hemos visto, se condenó a Vides Casanova (considerado como uno de los responsables del asesinato de los jesuitas) a pagar una indemnización millonaria. No obstante, dicha indemnización no se encuentra relacionada con el Caso Jesuitas.

La justicia, además de ser uno de los ejes de la justicia transicional, es a su vez una de las mejores garantías de no repetición. La impartición de justicia lleva implícito el mensaje de que no serán tolerados los crímenes y por lo tanto es uno de los mejores disuasivos de que se realicen en el futuro. En el Caso Jesuitas, al haber existido una completa impunidad, las 
garantías de no repetición en realidad no han existido. El hecho de que un crimen de Estado (como lo es el asesinato de los jesuitas) no haya sido investigado ni sancionado muestra que la sistematicidad con lo que se perpetuó sigue presente en el Estado salvadoreño. Esta idea se refuerza si tomamos en cuenta que el Estado no ha pedido perdón de ninguna forma por el crimen y que incluso quienes fueron señalados como responsables han sido ascendidos dentro de las Fuerzas Armadas o permanecido en altos puestos gubernamentales. El crimen de Estado sigue inserto en la estructura estatal, ya que también los gobiernos del FSLN lo han encubierto.

En materia de justicia, los resultados negativos están dados por la falta de justicia interna y por la acción decidida que hubo en su momento de sustraerse de la competencia de la Corte Interamericana de Derechos Humanos. Hoy el Estado salvadoreño ha decidido aceptar esta competencia en relación con los crímenes realizados durante el conflicto bélico. Sin embargo, por motivos procedimentales del Sistema Interamericano de Derechos Humanos, el Caso Jesuitas ya no podrá ser conocido por la Corte.

Los resultados positivos en materia de justicia se han dado, paradójicamente, gracias a Estados Unidos. Este país, que durante el conflicto bélico apoyó al gobierno militar salvadoreño, ahora ha echado a andar mecanismos para detener, deportar o extraditar a responsables de los crímenes del pasado inmediato. Los juicios realizados en Estados Unidos, a través de los cuales se han deportado a El Salvador a algunos militares y se extraditó a España a una figura de alto rango, son los logros más significativos y concretos en materia de justicia que se han obtenido en relación con el caso.

Gracias al juicio en España, se ha logrado una justicia que podríamos denominar como extrajurídica, ya que los señalados como responsables, además, han visto seriamente limitada su capacidad de circulación, al no poder abandonar territorio salvadoreño por temor a ser detenidos en otro país a causa de la querella conocida por la Audiencia Nacional española.

A través del análisis del Caso Jesuitas podemos corroborar la interrelación existente entre los cuatro ejes de la justicia transicional: los pocos 
resultados en el área de justicia han sido propiciadores de que en materia de verdad también existan profundas deficiencias. Un juicio interno apegado a derecho, en el cual se hubieran sentenciado a todos los responsables de los asesinatos (tanto materiales como intelectuales), habría significado un aporte enorme en cuestión de esclarecimiento histórico.

Los documentos relacionados con el caso, que han representado aportes a la verdad, han tenido resultados ambivalentes. El Informe de la Comisión de la Verdad, como vimos en el apartado correspondiente, identificó a los responsables y el modus operandi en que éstos realizaron los crímenes. No obstante, en este informe se incluyó el caso en el apartado titulado "Violencia contra los opositores por parte del Estado", lo que dio una imagen tergiversada de las víctimas y faltó a la verdad. El informe de la Comisión Interamericana tiene un gran valor en relación con el esclarecimiento histórico, debido a que en él se identificaron las violaciones a los derechos humanos resultantes de los asesinatos, y también el contexto histórico en el cual ocurrieron éstos. El hecho de que en este informe se haya analizado el derecho a la verdad hace que el Caso Jesuitas constituya un aporte en el desarrollo de este derecho dentro del Sistema Interamericano de Derechos Humanos. Sin embargo, el caso habría tenido mucha mayor resonancia y, por lo tanto, mayores resultados en relación con el conocimiento de la verdad, si la Corte Interamericana hubiera tenido la oportunidad de llevar a cabo el juicio correspondiente.

Dada la sistemática falta de voluntad política de los gobernantes salvadoreños para dar un tratamiento adecuado al caso jesuitas, las acciones deberán venir de parte de la sociedad civil. Sin embargo, al menos hasta ahora no se vislumbran acciones decididas de ésta, a pesar de que el proceso en España continúa vigente. La Universidad Centroamericana, que sería la institución más legitimada para impulsar la justicia en este caso, ha señalado que no está de acuerdo con el proceso que se lleva a cabo en España. Sin embargo, tampoco parece estar interesada en continuar con el que se había iniciado en El Salvador y que fue suspendido a causa de la emisión de LAGCP. Con la declaratoria de inconstitucionalidad de ésta, no existe ningún motivo aparente para la inactividad de la UCA. 
El actual panorama poco esperanzador, no obstante, no necesariamente tiene que perpetuarse. En materia de justicia transicional, se ven avances y retrocesos, comúnmente ocasionados por factores imprevistos. El estancamiento del Caso Jesuitas podría revertirse por alguno de estos factores.

BIBLIOGRAFÍA

ARTUCIO, ALEJANDRO. El Salvador. Un brecha a la impunidad aunque no bubo justicia. El juicio por el asesinato de los jesuitas. París: Comisión Internacional de Juristas, 1991.

Cardenal, Rodolfo (2011) Caso Jesuitas desnuda cultura de impunidad. En línea en: http://www.uca.edu.sv/publica/cartas/media/ archivo/d31001_pronunciamientodelauca.pdf (consultado el 10 de diciembre de 2017).

COMISIÓN DE LA VERDAD PARA El SALVADOR. Informe "De la locura a la esperanza: la guerra de 12 años en El Salvador". 1993.

COMISIÓN InTERAMERICANA DE DeRECHOS Humanos. Informe núm. 136/99, Caso10.488. Ignacio Ellacuría, S.J; Segundo Montes; S.J.; Armando López, S.J.; Ignacio Martín Baró, S.J.; Joaquín López y López, S.J; Juan Ramón Moreno, S.J.; Julia Elba Ramos; y Celina Mariceth Ramos, El Salvador, 22 de diciembre de 1999.

Informe anual 1989-1990. OEA/Ser.L/V/II.77rev.1. Doc.7. 17 de mayo de 1990.

CuÉllar, Benjamín. "La masacre en la uCA: de España a El Salvador". Revista Eca, Estudios Centroamericanos 66726 (2011).

"EDitorial" REVISTa ECA. Estudios Centroamericanos, San Salvador, Universidad Centroamericana 71745 (2016).

ESCAlante, Manuel. "Caso Jesuitas 1989-2016: un recorrido por la búsqueda de justicia y verdad". Revista Eca 71745 (2016).

ESTADO DE El SALVADOR. Instrumento de ratificación de aceptación de competencia de la Corte, depositado el 6 de junio de 1995. 
MeléndeZ, Florentín. Magistrado Primer vocal de la Sala de lo Constitucional. Voto disidente de la Resolución de Corte Plena sobre la denegatoria de asistencia en el marco del "Convenio de Cooperación Judicial en materia Penal entre la República de El Salvador y el Reino de España”. "El Derecho a la Verdad", San Salvador, 14 de julio de 2010.

TORO HuERTA, MAURICIO IVÁN DEL. "La jurisdicción universal en materia civil y el deber de reparación por violaciones graves a los derechos humanos". Anuario Mexicano de Derecho Internacional VII (2007).

UCA (2011). Pronunciamiento ante los acontecimientos nacionales derivados del avance del Caso Jesuitas en la Audiencia Nacional de España. Universidad Centroamericana José Simeón Cañas, San Salvador, 30 de agosto de 2011.

HEMEROGRAFÍA

Valencia, Daniel, Ricardo Vaquerano y Gabriel Labrad. El Faro. El Salvador, miércoles 8 de abril de 2015. Sección Nacionales.

El Mundo. Lunes 18 de abril de 2011. En línea http://www.elmundo.es/ america/2011/04/18/estados_unidos/1303141740.html (consultado el 3 de septiembre de 2017).

ENTREVISTAS REALIZADAS POR EVA LETICIA ORDUÑa TRUJILLO:

Entrevista a Benjamín Cuéllar el 11 de noviembre de 2017, en San Salvador, El Salvador.

Entrevista a Salvador Menéndez el 2 de diciembre de 2017, en San Salvador, El Salvador. 